\title{
Life Expectancy With and Without Cognitive Impairment among Brazilian Older
}

\section{Adults}

Flávia Cristina Drumond Andrade ${ }^{\mathrm{a}}$ (corresponding author), Ligiana Pires Corona ${ }^{\mathrm{b}}$, Maria Lúcia Lebrão $^{\mathrm{b}}$, Yeda Aparecida de Oliveira Duarte ${ }^{\mathrm{c}}$

a Department of Kinesiology and Community Health, College of Applied Health Sciences, University of Illinois, 1206 S. $4^{\text {th }}$ Street, Champaign, IL, 61820 USA; Tel: +1 $217333-$ 3675; Fax: +1 217 333-2766; E-mail: fandrade@illinois.edu

${ }^{\mathrm{b}}$ Department of Epidemiology, School of Public Health, University of São Paulo, Av. Dr. Arnaldo, 71, São Paulo, SP, Brazil

${ }^{\mathrm{c}}$ Medical-Surgical Nursing Department, School of Nursing, University of São Paulo, Av. Dr. Enéas de Carvalho Aguiar, 419, São Paulo, SP, Brazil

Acknowledgements:

The authors acknowledge Professor Jair Licio Ferreira Santos for his valuable comments reviewing the final text.

\begin{abstract}
Estimating the life expectancy with and without cognitive impairment in an older adult population is critical for understanding the burden of illness on individuals and their families, the health care system, and society at large. This paper presents and compares estimates of life expectancy with and without cognitive impairment for the noninstitutionalized population ages 60 years and older in São Paulo, Brazil, for the years 2000 and 2010. Life expectancy with and without cognitive impairment was calculated using the Sullivan method and prevalence estimates from data collection at two points (2000 and 2010) of the Health, Well-Being, and Aging Study (SABE). Results indicate that 60-year-old men in São Paulo in 2000 could expect to live 14.8 years and women 17.9 years without cognitive impairment. By 2010, life expectancy without cognitive impairment had increased to 17.1 years for men and 20.0 years for women. Length of life with cognitive impairment differed by gender (2.3 years for men and 3.7 years for women at age 60 in 2010). However, the absolute number of years with cognitive impairment remained relatively constant with age. The results indicate a trend for improvements in life expectancy without cognitive impairment over time in São Paulo. Adults in Brazil still face many years of cognitive impairment in their older years, particularly when compared with estimates from developed countries.
\end{abstract}


Life Expectancy with Cognitive Impairment

Keywords: life expectancy; cognitive impairment; older adults; Brazil; SABE Study. 
Life Expectancy with Cognitive Impairment

\section{INTRODUCTION}

Life expectancy at older ages has been increasing in Brazil. Among men, life expectancy at age 60 increased from 15.6 years in the period 1980-1985 to 19.5 years in the period 2005-2010 (CEPAL, 2007). Gains in life expectancy at age 60 were even larger among women, increasing from 18.0 to 22.5 years during the same period. As life expectancy has increased, researchers have begun to explore whether gains in life expectancy have translated into gains of healthy years or years lived with disease, disability, or cognitive impairment (Suthers, Kim, \& Crimmins, 2003).

An estimated 1 million individuals live with dementia in Brazil, and this number is expected to double in the next 20 years (Ferri, 2012). Conservative estimates indicate that total costs associated with dementia in Brazil reached $\$ 12.8$ billion (U.S.) in 2009, with direct costs accounting for $\$ 4.1$ billion, and informal care accounting for $\$ 8.7$ billion (Wimo, Winblad, \& Jönsson, 2010). Population-based studies show cognitive impairment rates in Brazil vary from 5\% among relatively healthy adults ages 60 and over (Chaves, Camozzato, Godinho, Piazenski, \& Kaye, 2009; Miranda et al., 2012) to $12 \%$ among institutionalized older adults (Marinho et al., 2010).

Prevalence of cognitive impairment increases with age (Plassman, Williams, Burke, Holsinger, \& Benjamin, 2010), so estimating the expected length of life with cognitive impairment helps us understand the burden of this condition for an average individual as he or she ages. Estimates of life expectancy with cognitive impairment are also important to determine service needs. Many studies estimating the life expectancy with and without cognitive impairment (or with and without dementia) have been conducted in developed countries (Dubois \& Hébert, 2006; Lièvre, Alley, \& Crimmins, 2008; Matthews, Jagger, Miller, Brayne, \& CFAS, 2009; Perenboom, Boshuizen, Breteler, Ott, \& Van de Water, 
Life Expectancy with Cognitive Impairment

1996; Ritchie, Mathers, \& Jorm, 1994; Ritchie, Robine, Letenneur, \& Dartigues, 1994; Roelands, van Oyen, \& Baro, 1994; Sauvaget, Jagger, \& Arthur, 2001; Sauvaget et al., 1997). But to our knowledge, no studies have been conducted in low- or middle-income countries. Given the limitations in the existent literature, the aim of this paper is to present and compare estimates of life expectancy with and without cognitive impairment among older adult residents of São Paulo, Brazil, for the years 2000 and 2010.

\section{MATERIALS AND METHODS}

\subsection{Prevalence data}

The data originated from the Saúde, Bem-Estar, e Envelhecimento [Health, WellBeing, and Aging] (SABE Study), a longitudinal study initiated in 2000 that collected information from a probabilistic sample of older adults (ages 60 years and older) residing in the city of São Paulo. This baseline sample (2000 A, $N=2,143)$ was obtained using a twostage stratified sampling method, following the framework of the 1995 National Household Sample Survey based on geographic areas of the city. Individuals ages 75 years and older were oversampled to compensate for the greater mortality rate in this age group. Details on the methodology of the SABE Study are described elsewhere (Lebrão \& Laurenti, 2005).

In 2006, a second wave was conducted. During this follow-up study, 1115 of the older adults who had participated in the baseline study were located and agreed to participate in this follow-up. In addition, a new sample of adults ages 60 through 64 was added (2006 B, $N=298$ ) following procedures similar to those used in the first wave.

A third data collection was conducted in $2010(N=1,345)$. This wave comprised respondents from the initial sample $(2010 \mathrm{~A}, n=748)$, respondents from the 2006 sample 
Life Expectancy with Cognitive Impairment

(2010 B, $n=242$ ), and respondents from a new 2010 sample of adults ages 60 through 64 $(2010 \mathrm{C}, n=355)$.

Sample weights for 2000 were calculated based on the 2000 census. In 2010, weights were recalculated based on the 2010 census. Our study focuses on the crosssectional prevalence rates obtained in 2000 and 2010.

The SABE Study was approved by the Ethics in Research Committee of the Faculty of Public Health of the University of São Paulo and the National Committee for Ethics in Research (CONEP) in Brazil. Participation in the survey was voluntary and a signed informed consent form was obtained. Our study was approved by the Institutional Review Board at the University of Illinois.

The SABE Study evaluated cognitive status using a modified version of the MiniMental State Examination (MMSE), which was validated for the study. Given the relatively low educational level of the South American older adult population, the adopted measure had 19 items that were less dependent upon educational level and used the cut-off point of 12 or less for cognitive impairment (Icaza \& Albala, 1999). Participants took the MMSE without the help of any auxiliary informants or proxy-respondents. Participants unable to respond to the questions received a score of 0 .

\subsection{Mortality data}

Mortality data were obtained from an official source, Fundação Sistema Estadual de Análise de Dados [State System for Data Analysis Foundation] (SEADE Foundation), which analyzes social, demographic, and economic data for the state of São Paulo. The 1999-2000-2001 and 2009-2010-2011 tables were used to generate the estimates for 2000 and 2010.

\subsection{Statistical Analysis}


Our study examines a large population-based survey of older adults. We based our calculations on prevalence data from the SABE Study waves of 2000 and 2010. Data were also disaggregated to include the covariate sex. Prevalence rates and $95 \%$ confidence intervals were calculated in Stata-SE version 12.0 using sampling weights. Tests for trend across ordered age groups were performed using the nptrend command.

We used the Sullivan method (Sullivan, 1971) to estimate life expectancy with and without cognitive impairment. The Sullivan method is the most widely used method to estimate healthy life expectancy (Imai \& Soneji, 2007). The method is based on a standard life table with two states, alive and dead. The alive state is subdivided into healthy (cognitively intact) and unhealthy (cognitively impaired) using observed prevalence of cognitive impairment (Barendregt, 1999; Jagger, Hauet, \& Brouard, 2001; Mathers, 1999). The main inputs are age-specific prevalence of healthy and unhealthy states in the population and age-specific mortality rates. The expected years in healthy state and unhealthy states are calculated by applying the age- and sex-specific cross-sectional prevalence rates of cognitive intact and cognitive impaired, respectively, to the personyears lived in different age categories derived from period life tables.

$$
\text { Healthy Life Expectancy }(\mathrm{HLE})_{x}=\frac{\sum\left(1-n \pi_{x}\right) n L_{x}}{l_{x}}
$$

and

$$
\text { Life Expectancy with Cognitive Impairment }_{x}=\frac{\sum\left(n \pi_{x}\right) n L_{x}}{l_{x}}
$$

where $\mathrm{HLE}_{\mathrm{x}}$ is the average number of years that an individual will live without cognitive impairment, starting from exact age $\mathrm{x}$ whereas life expectancy with cognitive 
impairment $_{\mathrm{x}}$ is the average number of years that an individual will live with any cognitive impairment, starting from exact age $\mathrm{x}$. The information needed to calculate these estimates are the prevalence of cognitive impairment for individuals aged $x$ to $x+n\left({ }_{n} \pi_{x}\right)$, which is obtained based on the SABE, the total number of years expected to be lived for individuals aged $x$ to $x+n\left({ }_{n} L_{x}\right)$ and the survival probability to exact age $x\left(1_{x}\right)$. These last two are obtained from the life table generated based on estimates provided by SEADE. Total life expectancy is the sum of healthy (HLE) and unhealthy years of life. These estimates are independent of the age structure of the population.

The Sullivan method has several advantages. In particular, this method combines the use of mortality and prevalence of healthy status (e.g., the absence of cognitive impairment)_-data that can be obtained from independent data sources. However, the method has been criticized for not incorporating mortality by health state $-\mathrm{a}$ factor that can be particularly important because cognitive decline is associated with higher mortality risks (Lièvre et al., 2008). Others (Lièvre et al., 2008; Sauvaget et al., 2001) have used multistate life tables, which incorporate mortality by health state and health transitions (i.e., incidence and recovery). We could have used multistate life-table models to analyze the data from the SABE Study, but decided not to for the following reasons: The second and third waves took place 6 and 10 years after the baseline, so we would have had to make strong and potentially unrealistic assumptions (for a discussion see Dubois \& Hebert, 2006). As well, there is evidence, at least for the United States, that multistate life tables and the Sullivan method have yielded similar results based on the Asset and Health Dynamics Among the Oldest Old (AHEAD) dataset (Lièvre et al., 2008; Suthers et al., 2003).

\section{RESULTS}


Among the 2,143 subjects interviewed in 2000, 1,764 were considered cognitively intact, and the remaining 379 were considered cognitively impaired. Out of the total 1,345 interviewed in 2010, 1,148 were considered cognitively intact and the other 197 were considered cognitively impaired. Table 1 shows the results related to the prevalence of cognitive impairment for 2000 and 2010 (weighted estimates) in the São Paulo population of adults ages 60 years and older. Prevalence of cognitive impairment among older adults in São Paulo decreased from $13.2 \%$ in 2000 to $10.4 \%$ in 2010 . Prevalence of cognitive impairment in 2000 was similar between men and women (12.7\% and $13.5 \%$, respectively). In 2010, prevalence of cognitive impairment was $8.8 \%$ among men and $11.4 \%$ among women, but although the difference between men and women increased, it was not statistically significant. In both years, prevalence of cognitive impairment was higher in older age groups $(p<0.001)$.

Table 2 shows the estimates for total life expectancy, life expectancy with and without cognitive impairment for both years based on the central estimates of the prevalence rates shown in Table 1. Results indicate that total life expectancy increased in São Paulo from 2000 to 2010. In 2000, TLE at age 60 was 17.5 years for men and 22.0 years for women. In 2010, TLE at age 60 had increased to 19.4 years for men and 23.7 years for women. The average number of years expected to be lived without cognitive impairment (HLE) also increased. Among men, HLE at age 60 was 14.8 years in 2000 and it reached 17.1 years in 2010, a gain of 2.3 years without cognitive impairment. Among women, HLE at age 60 increased from 17.9 in 2000 to 20.0 in 2010 - an increase of 2.1 years. The percentage of HLE to TLE also increased for both men and women. However, at each age, the percentage of healthy years to total years was always lower for women than it was for men. Although the absolute number of years with cognitive impairment remained 
relatively constant with age for both men and women in both time periods, that number was higher for women relative to men of the same age in 2000 and 2010. That is, for all years, older women had a higher TLE than men, but more of these years were spent with cognitive impairment.

Table 3 provides the low and high estimates for life expectancy with and without cognitive impairment based on the lower and upper limits of the $95 \%$ confidence intervals presented in Table 1. Results confirm the trend towards increasing the life expectancy without cognitive impairment and the gender differences in the number of years expected to be lived with cognitive impairment with older women living more years with cognitive impairment.

\section{DISCUSSION}

There are several important findings. First, even though the prevalence of cognitive impairment declined among older adults in Brazil between 2000 and 2010, this difference was not statistically significant in analyses using random effects models (results available upon request). Second, there are important differences in life expectancy with and without cognitive impairment by age and gender. Even though the absolute number of years with cognitive impairment remained relatively constant with age, which has been previously shown in the literature (Dubois \& Hébert, 2006; Lièvre et al., 2008; Matthews et al., 2009; Perenboom et al., 1996), the percentage of remaining healthy years declined sharply with age due to the decrease in TLE.

\subsection{Education}

In Brazil, as in other countries, having low educational level is associated with higher prevalence of dementia (Herrera, Caramelli, Silveira, \& Nitrini, 2002) and lower cognitive performance (Soares et al., 2012). 
Three studies (Lièvre, et al., 2008; Matthews, et al., 2009; Reuser, Willekens, \& Bonneux, 2011; Reuser, et al., 2011) have explored the impact of education on life expectancy with and without cognitive decline. All of them found that adults with fewer years of education were expected to live more years with cognitive impairment because education seems to delay the onset of cognitive impairment (Lièvre et al., 2008; Matthews et al., 2009; Reuser et al., 2011). The strong association between educational level and cognition at older ages has been explained by evidence showing that education can induce changes in brain function at younger ages, and those changes can attenuate the effects of neuropathology and thus help older adults maintain higher levels of cognition (Maurer, 2011; Reuser et al., 2011).

Therefore, the observed trend of reduced prevalence of cognitive impairment from 2000 to 2010 , even if not statistically significant, may at least in part be explained by the increased level of schooling of later-born cohorts. In 2000, the average length of schooling among the São Paulo population of adults ages 60 and older was 3.7 years, while in 2010 the average was 4.5 years. More specifically, the drop in prevalence of cognitive impairment among adults ages 60 through 64 years corresponded to an increase in the number of years they had attended school, from 4.7 years in 2000 to 5.9 years in 2010.

Although the instrument we used to assess cognitive impairment is only marginally influenced by schooling, it is well known that a higher level of education can act as a protective factor against cognitive impairment (see, e.g., Alley, Suthers, \& Crimmins, 2007). More studies are necessary to evaluate whether this downward trend in prevalence of cognitive impairment will continue in coming years.

\subsection{Comparisons with developed countries}


In comparison with estimates from studies of older adults in developed countries, results from our study indicate that HLE tends to be lower in Brazil and life expectancy with cognitive impairment tends to be higher. This means that older Brazilians, when compared to older adults in developed countries, live a higher percentage of their remaining years with cognitive impairment. Data from the baseline in this study showed that in 2000, men age 70 in São Paulo were expected to live $23 \%$ of their remaining years with cognitive impairment (2.6 out of 11.5 years) and women $28 \%$ ( 4.1 out of 14.7 years). In comparison, in Canada in 1991, the percentage of remaining years with cognitive impairment at age 70 was $21 \%$ for men (2.6 out of 12.5 years) and $24 \%$ for women (3.7 out of 15.3 years) (Dubois \& Hébert, 2006).

Based on a large longitudinal study in the United Kingdom, Matthews et al. (2009) estimated life expectancy with moderate-to-severe cognitive impairment at age 70 to be 1.3 years of $12.0(11 \%)$ for men and 2.9 years of $15.3(19 \%)$ for women. The percentage of years expected to be lived with cognitive impairment was also low in the United States: Lièvre et al. (2008), based on four waves (1993-2000) of the National Institute on Agingsponsored AHEAD study, estimated that 70-year-old adults could expect to live 1.3 years of a 14.4-year TLE (9\%) with cognitive decline. Another analysis based on the U.S. Health and Retirement Study estimated that 55-year-old men could expect to live with cognitive impairment for 2.5 years of a 25-year TLE (10\%) and that 55-year-old women could expect to live with cognitive impairment for 3.8 years of a 29.4-year TLE (13\%) (Reuser et al., 2011).

Differences in life expectancy with and without cognitive impairment between older adults in developed and developing countries can be attributed to a number of factors: They can result from differences in the measurement of cognitive impairment or in the methods 
used to estimate life expectancy with and without cognitive impairment. As mentioned in section 4.1, educational level can affect cognitive performance, and the average length of schooling for older men and women in Brazil is much less than that of older adults in developed countries. And, educational level can have an indirect effect on the mediation of other cognitive resources across the life course, such as occupation, health, or lifestyle (Maurer, 2011).

\subsection{Age}

Prevalence of cognitive impairment increases with age, and data indicate that older adults can be expected to live a higher percentage of their remaining years with cognitive impairment. Previous studies conducted in Brazil showed that chronological age was an independent predictor for lower cognitive performance (Soares et al., 2012) and that older age was associated with faster cognitive decline over time (Castro-Costa et al., 2011).

\subsection{Sex}

As evidenced in this study and in the existing literature, women live longer (Verbrugge, 1989). However, we also found that women face a greater number of years and a higher percentage of remaining years with cognitive impairment (Dubois \& Hébert, 2006; Matthews et al., 2009; Reuser et al., 2011). Previous studies in Brazil have shown that women have lower scores on the MMSE than men (Maurer, 2011; Soares et al., 2011). However, other studies found that women had higher scores on the baseline, but faced faster cognitive decline over time (Castro-Costa et al., 2011). Some have argued that the higher impact of cognitive impairment in women can be, at least in part, attributed to differences in educational levels, because among older adults, educational attainment among women is lower than among men: Maurer (2011) found that more than half of the overall difference in late-life cognition was a result of gender differences in educational 
Life Expectancy with Cognitive Impairment

attainment. Yount (2008) demonstrated that $83 \%$ of the gender gap in mean MMSE scores was attributable to differences in men's and women's life course, mainly education.

\subsection{Limitations}

This study has some limitations. Our estimates of cognitive impairment are based only in community-living older adults, because institutionalized respondents were not included in the SABE Study. However, we do not expect this to have much of an effect on our estimates for the following reasons: A study in Brazil found that institutionalization of older adults was associated with worse cognitive performance (Plati, Covre, Lukasova, \& de Macedo, 2006). On the other hand, a later study found no difference in levels of cognitive impairment between residents in long-stay institutions and community-living older adults in Brazil (Marinho et al., 2010). As well, the institutionalized population in Brazil is small, because families remain the main source of care for older adults (Camarano \& Kanso, 2010). Therefore, we believe that this bias is likely to be trivial.

Another limitation refers to the use of specific cutoffs of the MMSE. As expected the use of different cutoffs to measure cognitive impairment can alter the number of years lived with and without cognitive impairment, and so the comparison between our results and other previous studies should be taken carefully. In addition, this study estimates are based on a modified version of the MMSE. This measure was adopted in the SABE study because other studies had already shown that older adults with low levels of education were more likely to become cognitively impaired and do so at an earlier age (Lièvre et al., 2008), therefore given the fact that Brazilian older adults have a very low educational level, this modified instrument is an attempt to reduces the influence of schooling. If we had used the complete version of MMSE, our estimates would be affected given that a large percentage of our study population has low educational levels. Besides, the MMSE instrument also 
other limitations such as the limited usefulness for differential diagnosis, use of different cut-off scores and sometimes poor translations -- all of which have been widely explored in the literature (Folstein \& Folstein, 2010). However, the instrument is widely used in research to measure cognitive impairment, and it is also considered a good tool for measuring general cognitive ability, which is especially useful in epidemiologic studies (Ismail, Rajji, \& Shulman, 2010).

The fact that the study was conducted in São Paulo may also be a source of bias, because it uses a population of older adults in the country's largest city. It is possible that, because São Paulo offers the largest and most comprehensive network of health services in the country, the estimates presented here may differ from the rest of the country. On the other hand, the city has a very diverse older adult (e.g. sociodemographic levels, racial groups, migration histories), which have different levels of access to these services. Inequality in access to health services was higher in São Paulo than for the other cities participating in the SABE multicenter study in 2000 (Noronha \& Andrade, 2005), which reflects the diversity and disparities found in the city and in Brazil as a whole. Therefore, even though the data are not representative for the country, it is helpful to understand the trends seeing in São Paulo, given its diverse and dynamic population. As for other countries in South America, Brazil still lacks data on cognition in a larger and representative sample, therefore this study contributes to this knowledge by providing estimates for the largest city in Brazil.

\subsection{Implications of the research}

Cognitive decline often can lead to dementia and Alzheimer's Disease (Fisk, Merry, \& Rockwood, 2003), higher occurrence of falls (Welmerink, Longstreth, Lyles, \& 
Life Expectancy with Cognitive Impairment

Fitzpatrick, 2010), and consequent dependence on caregivers for activities of daily living (Alexandre et al., 2012; Avila-Funes et al., 2011). As a result, cognitive impairment increases the demand for health services, especially high-cost procedures and medications. However, Brazil, like most developing countries, does not have sufficiently organized health care structures or policies to cope with the rapid aging of the population and associated increase in costs.

The current Politica Nacional de Saúde do Idoso [National Policy for the Health of the Elderly] (PNSI) in Brazil proposes several programs to improve the health and wellbeing of older adults. Programs implemented by the federal government currently focus on immunization, distribution of medications for prevalent diseases, and cataract surgery (Miyata, Vagetti, Fanhani, Pereira, \& Andrade, 2005). However, programs such as adult day health care and home health care for older adults are still not well-developed, and few states are acting according to the PNSI guidelines (Miyata et al., 2005).

The programs aimed at training health care professionals have also been slow to begin and/or develop. Specialized trained health care professionals are needed for the regular and careful assessment of cognitive decline, so that programs and policies can be implemented among the appropriate target groups. Trained health care professionals are also needed to lead activities that can improve social engagement and lower functional loss among older adults.

Recent studies conducted in Brazil have shown positive results for interventions related to cognition. Older adult residents in institutions had lower functional loss and better social engagement when they participated in stimulating activities and interventions based on reminiscence using a life-history approach (Azcurra, 2012; Plati et al., 2006). Other programs, such as home health care for older adults, need to be implemented to 
address gender differentials in cognitive decline and care. In Brazil, most of the care of older adults is provided by family members, particularly spouses and children (Del Duca, Thumé, \& Hallal, 2011). Because caring for a spouse is associated with cognitive decline (Vitaliano, Murphy, Young, Echeverria, \& Borson, 2011), Brazilian older women are disproportionately at risk, given that they are more likely to provide care to their (often older) husbands.

\section{CONCLUSION}

Cognitive impairment is a major health problem at older ages. This study provides the first estimates of life expectancy with and without cognitive impairment for older adults in Brazil, adding to a growing body of literature that estimates life expectancy with and without cognitive impairment (Dubois \& Hébert, 2006; Lièvre et al., 2008; Matthews et al., 2009; Perenboom et al., 1996; Ritchie, Mathers, et al., 1994; Ritchie, Robine, et al., 1994; Roelands et al., 1994; Sauvaget et al., 2001; Sauvaget et al., 1997).

Our findings suggest that older Brazilians live a higher percentage of their remaining lives with cognitive impairment than their counterparts from more developed countries. They also suggest important gender differences: Older Brazilian women live longer lives, but they live a greater number and a higher percentage of their remaining years with cognitive impairment. These estimates of life expectancy with and without cognitive impairment for older adults are critical for understanding the burden of cognitive impairment and the services needed by those with the condition as well as their caregivers.

\section{Conflict of interest statement}

The authors report no conflicts of interest.

\section{Study sponsors}


SABE Study is funded by São Paulo Research Foundation (Fundação de Amparo à Pesquisa do Estado de São Paulo - FAPESP): grant numbers: 1999/05125 (wave 1); 2005/54947-2 (wave 2); 2009/53778-3 (wave 3). FAPESP also provided funding for LCP (2010/02779-7; PhD candidate scholarship). The authors gratefully acknowledge the support from Lemann Institute for Brazilian Studies at the University of Illinois at UrbanaChampaign. 
Life Expectancy with Cognitive Impairment

\section{REFERENCES}

Alley, D., Suthers, K., \& Crimmins, E. (2007). Education and cognitive decline in older Americans results from the AHEAD sample. Research on Aging, 29(1), 73-94.

Alexandre, T. D., Corona, L. P., Nunes, D. P., Santos, J. L. F., Duarte, Y. A. D., \& Lebrão, M. L. (2012). Gender differences in incidence and determinants of disability in activities of daily living among elderly individuals: SABE study. Archives of Gerontology and Geriatrics, 55(2), 431-437.

Avila-Funes, J. A., Pina-Escudero, S. D., Aguilar-Navarro, S., Gutierrez-Robledo, L. M., Ruiz-Arregui, L., \& Amieva, H. (2011). Cognitive impairment and low physical activity are the components of frailty more strongly associated with disability. Journal of Nutrition, Health and Aging, 15(8), 683-689.

Azcurra, D. J. L. S. (2012). A reminiscence program intervention to improve the quality of life of long-term care residents with Alzheimer's Disease: A randomized controlled trial. Revista Brasileira de Psiquiatria., 34(4), 422-433.

Barendregt, J. J. (1999). Incidence- and prevalence-based SMPHs: Making the twain meet.

In C. Murray, J. Salomon, C. Mathers \& A. Lopez (Eds.), Summary measures of population health: Concepts, ethics, measurement and applications (pp. 221-231). Geneva: World Health Organization.

Camarano, A. A., \& Kanso, S. (2010). As instituições de longa permanência para idosos no Brasil [The long-term institutions for the elderly in Brazil]. Revista Brasileira de Estudos de População, 27, 232-235 (in Portuguese).

Castro-Costa, E., Dewey, M. E., Uchôa, E., Firmo, J. O., Lima-Costa, M. F., \& Stewart, R. (2011). Trajectories of cognitive decline over 10 years in a Brazilian elderly 
Life Expectancy with Cognitive Impairment

population: The Bambuí Cohort Study of Aging. Cadernos de Saude Publica, 27(Suppl 3), S345-350 (in Portuguese).

CEPAL. (2007). América Latina y el Caribe. Observatorio Demográfico No 4: Mortalidad [Latin America and the Caribbean: Demographic Observatory N.4: Mortality]. Santiago de Chile: Centro Latinoamericano y Caribeño de Demografía (CELADE) - División de Población de la CEPAL (in Spanish).

Chaves, M. L., Camozzato, A. L., Godinho, C., Piazenski, I., \& Kaye, J. (2009). Incidence of mild cognitive impairment and Alzheimer disease in Southern Brazil. Journal of Geriatric Psychiatry and Neurology, 22(3), 181-187.

Del Duca, G. F., Thumé, E., \& Hallal, P. C. (2011). Prevalence and factors associated with home care among older adults. Revista de Saúde Pública, 45(1), 113-120.

Dubois, M. F., \& Hébert, R. (2006). Cognitive-impairment-free life expectancy for Canadian seniors. Dementia and Geriatric Cognitive Disorders, 22(4), 327-333.

Ferri, C. P. (2012). Population ageing in Latin America: Dementia and related disorders. Revista Brasileira de Psiquiatria, 34(4), 371-374 (in Portuguese).

Fisk, J. D., Merry, H. R., \& Rockwood, K. (2003). Variations in case definition affect prevalence but not outcomes of mild cognitive impairment. Neurology, 61(9), $1179-1184$.

Folstein, M., \& Folstein, S. (2010). Invited reply to "The death knoll for the MMSE: Has it outlived its purpose?" Journal of Geriatric Psychiatry and Neurology, 23(3), 158159.

Herrera, E., Caramelli, P., Silveira, A. S., \& Nitrini, R. (2002). Epidemiologic survey of dementia in a community-dwelling Brazilian population. Alzheimer Disease and Associated Disorders, 16(2), 103-108. 
Life Expectancy with Cognitive Impairment

Icaza, M. C., \& Albala, C. (1999). Projeto SABE. Mini Mental State Examination (MMSE) del Studio de demencia en Chile: análisis estatístico (pp. 1-18). Washington: OPAS (in Spanish). XXXVI Reunión del Comitê Asesor de Investigaciones en SaludEncuestra Multicêntrica - Salud Beinestar y Envejecimeiento(SABE) en América Latina e el Caribe - Informe preliminar.

Imai, K., \& Soneji, S. (2007). On the estimation of disability-free life expectancy. Journal of the American Statistical Association, 102(480), 1199-1211.

Ismail, Z., Rajji, T. K., \& Shulman, K. I. (2010). Brief cognitive screening instruments: An update. International Journal of Geriatric Psychiatry, 25(2), 111-120.

Jagger, C., Hauet, E., \& Brouard, N. (2001). Health expectancy calculation by the Sullivan Method: A practical guide. Leicester: Euro-REVES.

Lebrão, M. L., \& Laurenti, R. (2005). Saúde, bem-estar e envelhecimento: O estudo SABE no Município de São Paulo [Health, Wellbeing and Aging: the SABE study in São Paulo]. Revista Brasileira de Epidemiologia, 8, 127-141 (in Portuguese).

Lièvre, A., Alley, D., \& Crimmins, E. M. (2008). Educational differentials in life expectancy with cognitive impairment among the elderly in the United States. Journal of Aging and Health, 20(4), 456-477.

Marinho, P. E., Melo, K. P., Apolinário, A. D., Bezerra, E., Freitas, J., Melo, D. M., ...Dornelas de Andrade, A.] (2010). Undertreatment of depressive symptomatology in the elderly living in long stay institutions (LSIs) and in the community in Brazil. Archives of Gerontology and Geriatrics, 50(2), 151-155.

Mathers, C. (1999). Health expectancies: An overview and critical appraisal. In C. Murray, J. A. Salomon, C. D. Mathers \& A. D. Lopez (Eds.), Summary measures of 
Life Expectancy with Cognitive Impairment

population health: Concepts, ethics, measurement and applications (pp. 177-204). Geneva: World Health Organization.

Matthews, F. E., Jagger, C., Miller, L. L., Brayne, C., \& MRC CFAS Neuropathology Group; (2009). Education differences in life expectancy with cognitive impairment. Journals of Gerontology, Series A, Biological Sciences and Medical Sciences, 64(1), 125-131.

Maurer, J. (2011). Education and male-female differences in later-life cognition: International evidence from Latin America and the Caribbean. Demography, 48(3), 915-930.

Miranda, L. . P., Silveira, M. F., Oliveira, T. L., Alves, S. F. F., Junior, H. M., Batista, A. U. D., Bonan, P. R.F. (2012). Cognitive impairment, the Mini-Mental State Examination and socio-demographic and dental variables in the elderly in Brazil. Gerodontology, 29(2), e34-e40.

Miyata, D. F., Vagetti, G. C., Fanhani, H. R., Pereira, J. G., \& Andrade, O. G. (2005). Políticas e programas na atenção à saúde do idoso: um panorama nacional [Policies and programs for health care of the elderly: a national overview]. Arquivos de Ciências da Saúde da Unipar, Umuarama, 9(2), 135-140 (in Portuguese).

Noronha, K. V. M. D. S., Andrade, M. V (2005). Desigualdades sociais em saúde e na utilização dos serviços de saúde entre os idosos na América Latina [Social inequality in health and the utilization of health services among the elderly in Latin America]. Rev Panam Salud Publica, 17, 410-8. 
Life Expectancy with Cognitive Impairment

Perenboom, R. J., Boshuizen, H. C., Breteler, M. M., Ott, A., \& Van de Water, H. P. (1996). Dementia-free life expectancy (DemFLE) in the Netherlands. Social Science and Medicine, 43(12), 1703-1707.

Plassman, B. L., Williams, J. W., Burke, J. R., Holsinger, T., \& Benjamin, S. (2010). Systematic review: Factors associated with risk for and possible prevention of cognitive decline in later life. Annals of Internal Medicine, 153(3), 182-193.

Plati, M. C., Covre, P., Lukasova, K., \& de Macedo, E. C. (2006). Depressive symptoms and cognitive performance of the elderly: Relationship between institutionalization and activity programs. Revista Brasileira de Psiquiatria, 28(2), 118-121 (in Portuguese).

Reuser, M., Willekens, F. J., \& Bonneux, L. (2011). Higher education delays and shortens cognitive impairment: A multistate life table analysis of the US Health and Retirement Study. European Journal of Epidemiology, 26(5), 395-403.

Ritchie, K., Mathers, C., \& Jorm, A. (1994). Dementia-free life expectancy in Australia. Australian Journal of Public Health, 18(2), 149-152.

Ritchie, K., Robine, J. M., Letenneur, L., \& Dartigues, J. F. (1994). Dementia-free life expectancy in France. American Journal of Public Health, 84(2), 232-236.

Roelands, M., van Oyen, H., \& Baro, F. (1994). Dementia-free life expectancy in Belgium. European Journal of Public Health, 4(1), 33-37.

Sauvaget, C., Jagger, C., \& Arthur, A. J. (2001). Active and cognitive impairment-free life expectancies: Results from the Melton Mowbray 75+ health checks. Age and Ageing, 30(6), 509-515. 
Life Expectancy with Cognitive Impairment

Sauvaget, C., Tsuji, I., Minami, Y., Fukao, A., Hisamichi, S., Asano, H., Sato, M. (1997). Dementia-free life expectancy among elderly Japanese. Gerontology, 43(3), 168175.

Soares, L. M., Cachioni, M., Falcão, D. V., Batistoni, S. S., Lopes, A., Neri, A. L., Yassuda, M. S. (2012). Determinants of cognitive performance among community dwelling older adults in an impoverished sub-district of São Paulo in Brazil. Archives of Gerontology and Geriatrics, 54(2), e187-192.

Sullivan, D. F. (1971). A single index of mortality and morbidity. HSMHA Health Reports, 86(4), 347-354.

Suthers, K., Kim, J. K., \& Crimmins, E. (2003). Life expectancy with cognitive impairment in the older population of the United States. Journals of Gerontology, Series B, Psychological Sciences and Social Sciences, 58(3), S179-186.

Verbrugge, L. M. (1989). The twain meet: Empirical explanations of sex differences in health and mortality. Journal of Health and Social Behavior, 30(3), 282-304.

Vitaliano, P. P., Murphy, M., Young, H. M., Echeverria, D., \& Borson, S. (2011). Does caring for a spouse with dementia promote cognitive decline? A hypothesis and proposed mechanisms. Journal of the American Geriatrics Society, 59(5), 900-908.

Welmerink, D. B., Longstreth, W. T., Lyles, M. F., \& Fitzpatrick, A. L. (2010). Cognition and the risk of hospitalization for serious falls in the elderly: Results from the Cardiovascular Health Study. Journals of Gerontology, Series A, Biological Sciences and Medical Sciences, 65(11), 1242-1249.

Wimo, A., Winblad, B., \& Jönsson, L. (2010). The worldwide societal costs of dementia: Estimates for 2009. Alzheimer's and Dementia, 6(2), 98-103. 
Life Expectancy with Cognitive Impairment

Yount, K. M. (2008). Gender, resources across the life course, and cognitive functioning in Egypt. Demography, 45(4), 907-926. 
Life Expectancy with Cognitive Impairment

\section{Table 1}

Prevalence of Cognitive Impairment among Older Adults in São Paulo, Brazil: 2000 and 2010 (Weighted Estimates)

\begin{tabular}{|c|c|c|c|c|}
\hline \multirow[t]{2}{*}{$\begin{array}{l}\text { Sex and age } \\
\text { groups }\end{array}$} & \multicolumn{2}{|r|}{2000} & \multicolumn{2}{|r|}{2010} \\
\hline & $\%$ & $95 \% \mathrm{CI}$ & $\%$ & $95 \% \mathrm{CI}$ \\
\hline Total & 13.2 & {$[11.4,15.2]$} & 10.4 & {$[8.5,12.7]$} \\
\hline $60-64$ & 6.0 & {$[3.8,9.1]$} & 2.8 & {$[1.2,6.4]$} \\
\hline $65-69$ & 8.0 & {$[5.5,11.7]$} & 5.1 & {$[2.5,10.1]$} \\
\hline $70-74$ & 13.4 & {$[9.7,18.2]$} & 10.3 & {$[6.2,16.6]$} \\
\hline $75-79$ & 18.5 & {$[13.9,24.3]$} & 12.4 & {$[8.3,18.2]$} \\
\hline $80-84$ & 30.0 & {$[23.6,37.2]$} & 26.7 & {$[19.8,34.9]$} \\
\hline $85+$ & 56.4 & {$[48.7,63.8]$} & 45.3 & {$[35.3,55.7]$} \\
\hline Men & 12.6 & {$[10.1,15.8]$} & 8.8 & {$[6.3,12.2]$} \\
\hline $60-64$ & 6.4 & {$[3.5,11.4]$} & 1.7 & {$[0.4,7.0]$} \\
\hline $65-69$ & 9.5 & {$[5.4,16.2]$} & 5.2 & {$[1.2,19.5]$} \\
\hline $70-74$ & 15.6 & {$[10.3,22.8]$} & 11.0 & {$[5.4,21.3]$} \\
\hline $75-79$ & 16.2 & {$[11.6,22.2]$} & 16.4 & {$[8.6,29.0]$} \\
\hline $80-84$ & 24.3 & {$[18.3,31.6]$} & 19.8 & {$[10.5,34.2]$} \\
\hline $85+$ & 51.6 & {$[41.8,61.2]$} & 38.5 & {$[26.7,52.0]$} \\
\hline Women & 13.5 & {$[11.6,15.8]$} & 11.4 & {$[9.1,14.2]$} \\
\hline $60-64$ & 5.6 & {$[3.3,9.3]$} & 3.7 & {$[1.7,7.8]$} \\
\hline $65-69$ & 6.9 & {$[4.3,11.0]$} & 5.0 & {$[2.2,10.9]$} \\
\hline $70-74$ & 11.8 & {$[7.4,18.4]$} & 9.8 & {$[5.2,17.7]$} \\
\hline $75-79$ & 19.9 & {$[14.1,27.5]$} & 10.2 & {$[6.0,17.0]$} \\
\hline $80-84$ & 32.6 & {$[24.5,42.0]$} & 29.6 & {$[20.9,39.9]$} \\
\hline $85+$ & 58.9 & {$[49.0,68.2]$} & 49.0 & {$[38.0,60.1]$} \\
\hline
\end{tabular}

Note. $\mathrm{CI}=$ confidence interval. 
Life Expectancy with Cognitive Impairment

Table 2

Total Life Expectancy, Life Expectancy without and with Cognitive Impairment among Older Adults in São Paulo, Brazil: 2000 and 2010

\begin{tabular}{|c|c|c|c|c|c|c|c|c|c|c|}
\hline \multirow[b]{2}{*}{ Sex and age } & \multicolumn{5}{|c|}{2000} & \multicolumn{5}{|c|}{2010} \\
\hline & TLE & HLE & $\mathrm{SE}$ & $\begin{array}{l}\% \text { healthy } \\
\text { years } \\
\text { remaining }\end{array}$ & $\begin{array}{l}\text { Life } \\
\text { expectancy } \\
\text { with } \\
\text { cognitive } \\
\text { impairment }\end{array}$ & TLE & HLE & SE & $\begin{array}{l}\% \text { healthy } \\
\text { years } \\
\text { remaining }\end{array}$ & $\begin{array}{c}\text { Life } \\
\text { expectancy } \\
\text { with } \\
\text { cognitive } \\
\text { impairment }\end{array}$ \\
\hline \multicolumn{11}{|l|}{ Total } \\
\hline 60 & 20.0 & 16.5 & 0.15 & 82.5 & 3.5 & 21.6 & 18.6 & 0.20 & 86.1 & 3.0 \\
\hline 65 & 16.5 & 13.1 & 0.15 & 79.4 & 3.5 & 17.9 & 14.9 & 0.21 & 83.2 & 3.1 \\
\hline 70 & 13.4 & 9.9 & 0.15 & 73.9 & 3.5 & 14.5 & 11.4 & 0.21 & 78.6 & 3.1 \\
\hline 75 & 10.5 & 7.1 & 0.15 & 67.6 & 3.4 & 11.4 & 8.4 & 0.22 & 73.7 & 3.1 \\
\hline 80 & 8.1 & 4.6 & 0.17 & 56.8 & 3.5 & 8.7 & 5.6 & 0.23 & 64.4 & 3.2 \\
\hline 85 & 6.1 & 2.7 & 0.20 & 44.3 & 3.5 & 6.4 & 3.5 & 0.24 & 54.7 & 2.9 \\
\hline \multicolumn{11}{|l|}{ Men } \\
\hline 60 & 17.5 & 14.8 & 0.20 & 84.6 & 2.7 & 19.4 & 17.1 & 0.29 & 88.1 & 2.3 \\
\hline 65 & 14.3 & 11.7 & 0.20 & 81.8 & 2.6 & 16.0 & 13.6 & 0.31 & 85.0 & 2.4 \\
\hline 70 & 11.5 & 8.9 & 0.20 & 77.4 & 2.6 & 12.8 & 10.4 & 0.32 & 81.3 & 2.4 \\
\hline 75 & 9.1 & 6.6 & 0.18 & 72.5 & 2.5 & 10.1 & 7.7 & 0.33 & 76.2 & 2.4 \\
\hline 80 & 7.0 & 4.4 & 0.21 & 62.9 & 2.6 & 7.7 & 5.5 & 0.32 & 71.4 & 2.2 \\
\hline 85 & 5.4 & 2.6 & 0.27 & 48.1 & 2.8 & 5.7 & 3.5 & 0.34 & 61.4 & 2.2 \\
\hline \multicolumn{11}{|l|}{ Women } \\
\hline 60 & 22.0 & 17.9 & 0.22 & 81.4 & 4.1 & 23.7 & 20.0 & 0.28 & 84.4 & 3.7 \\
\hline 65 & 18.2 & 14.1 & 0.22 & 77.5 & 4.1 & 19.6 & 16.0 & 0.28 & 81.6 & 3.6 \\
\hline 70 & 14.7 & 10.6 & 0.22 & 72.1 & 4.1 & 15.9 & 12.2 & 0.29 & 76.7 & 3.7 \\
\hline 75 & 11.5 & 7.4 & 0.23 & 64.3 & 4.1 & 12.4 & 8.8 & 0.29 & 71.0 & 3.6 \\
\hline 80 & 8.7 & 4.7 & 0.25 & 54.0 & 4.0 & 9.4 & 5.6 & 0.31 & 59.6 & 3.8 \\
\hline 85 & 6.5 & 2.7 & 0.28 & 41.5 & 3.8 & 6.8 & 3.5 & 0.32 & 51.5 & 3.3 \\
\hline
\end{tabular}


Life Expectancy with Cognitive Impairment

Note. TLE = total life expectancy; HLE = healthy life expectancy (life expectancy without cognitive impairment); SE = standard error. 
Life Expectancy with Cognitive Impairment

\section{Table 3}

Low and High Estimates for Life Expectancy with and without Cognitive Impairment based on 95\% Confidence Interval among Older Adults in São Paulo, Brazil: 2000 and 2010

\begin{tabular}{|c|c|c|c|c|c|c|c|c|}
\hline \multirow{3}{*}{$\begin{array}{l}\text { Sex and } \\
\text { age }\end{array}$} & \multicolumn{4}{|c|}{2000} & \multicolumn{4}{|c|}{2010} \\
\hline & \multicolumn{2}{|c|}{$\begin{array}{l}\text { Life expectancy without } \\
\text { cognitive impairment }\end{array}$} & \multicolumn{2}{|c|}{$\begin{array}{l}\text { Life expectancy with } \\
\text { cognitive impairment }\end{array}$} & \multicolumn{2}{|c|}{$\begin{array}{l}\text { Life expectancy without } \\
\text { cognitive impairment }\end{array}$} & \multicolumn{2}{|c|}{$\begin{array}{l}\text { Life expectancy with } \\
\text { cognitive impairment }\end{array}$} \\
\hline & Low & High & Low & High & Low & High & Low & High \\
\hline \multicolumn{9}{|l|}{ Total } \\
\hline 60 & 15.6 & 17.3 & 2.7 & 4.4 & 17.3 & 19.6 & 2.1 & 4.3 \\
\hline 65 & 12.2 & 13.8 & 2.7 & 4.3 & 13.6 & 15.8 & 2.2 & 4.3 \\
\hline 70 & 9.1 & 10.6 & 2.8 & 4.3 & 10.3 & 12.3 & 2.3 & 4.2 \\
\hline 75 & 6.4 & 7.7 & 2.8 & 4.2 & 7.5 & 9.1 & 2.3 & 4.0 \\
\hline 80 & 4.0 & 5.2 & 2.9 & 4.1 & 4.8 & 6.3 & 2.4 & 4.0 \\
\hline 85 & 2.2 & 3.1 & 3.0 & 3.9 & 2.8 & 4.2 & 2.3 & 3.6 \\
\hline \multicolumn{9}{|l|}{ Males } \\
\hline 60 & 13.7 & 15.6 & 1.8 & 3.8 & 15.0 & 18.2 & 1.2 & 4.4 \\
\hline 65 & 10.7 & 12.4 & 1.9 & 3.6 & 11.5 & 14.7 & 1.3 & 4.4 \\
\hline 70 & 8.1 & 9.6 & 1.9 & 3.4 & 8.8 & 11.4 & 1.4 & 4.0 \\
\hline 75 & 6.0 & 7.2 & 1.9 & 3.1 & 6.4 & 8.7 & 1.4 & 3.7 \\
\hline 80 & 3.9 & 5.0 & 2.0 & 3.1 & 4.4 & 6.3 & 1.4 & 3.3 \\
\hline 85 & 2.1 & 3.1 & 2.3 & 3.3 & 2.7 & 4.2 & 1.5 & 3.0 \\
\hline \multicolumn{9}{|l|}{ Females } \\
\hline 60 & 16.5 & 19.0 & 3.1 & 5.5 & 18.2 & 21.2 & 2.5 & 5.4 \\
\hline 65 & 12.9 & 15.2 & 3.1 & 5.4 & 14.4 & 17.1 & 2.5 & 5.3 \\
\hline 70 & 9.4 & 11.6 & 3.1 & 5.3 & 10.8 & 13.3 & 2.6 & 5.1 \\
\hline 75 & 6.4 & 8.3 & 3.2 & 5.1 & 7.7 & 9.8 & 2.6 & 4.8 \\
\hline 80 & 3.9 & 5.5 & 3.2 & 4.8 & 4.6 & 6.6 & 2.8 & 4.8 \\
\hline 85 & 2.1 & 3.3 & 3.2 & 4.4 & 2.7 & 4.2 & 2.6 & 4.1 \\
\hline
\end{tabular}

